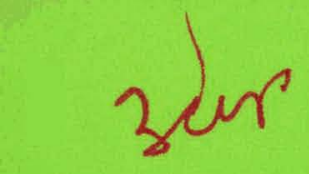

\title{
Junction Field Effect Transistor Degradation Caused by Electrostatic Discharge
}
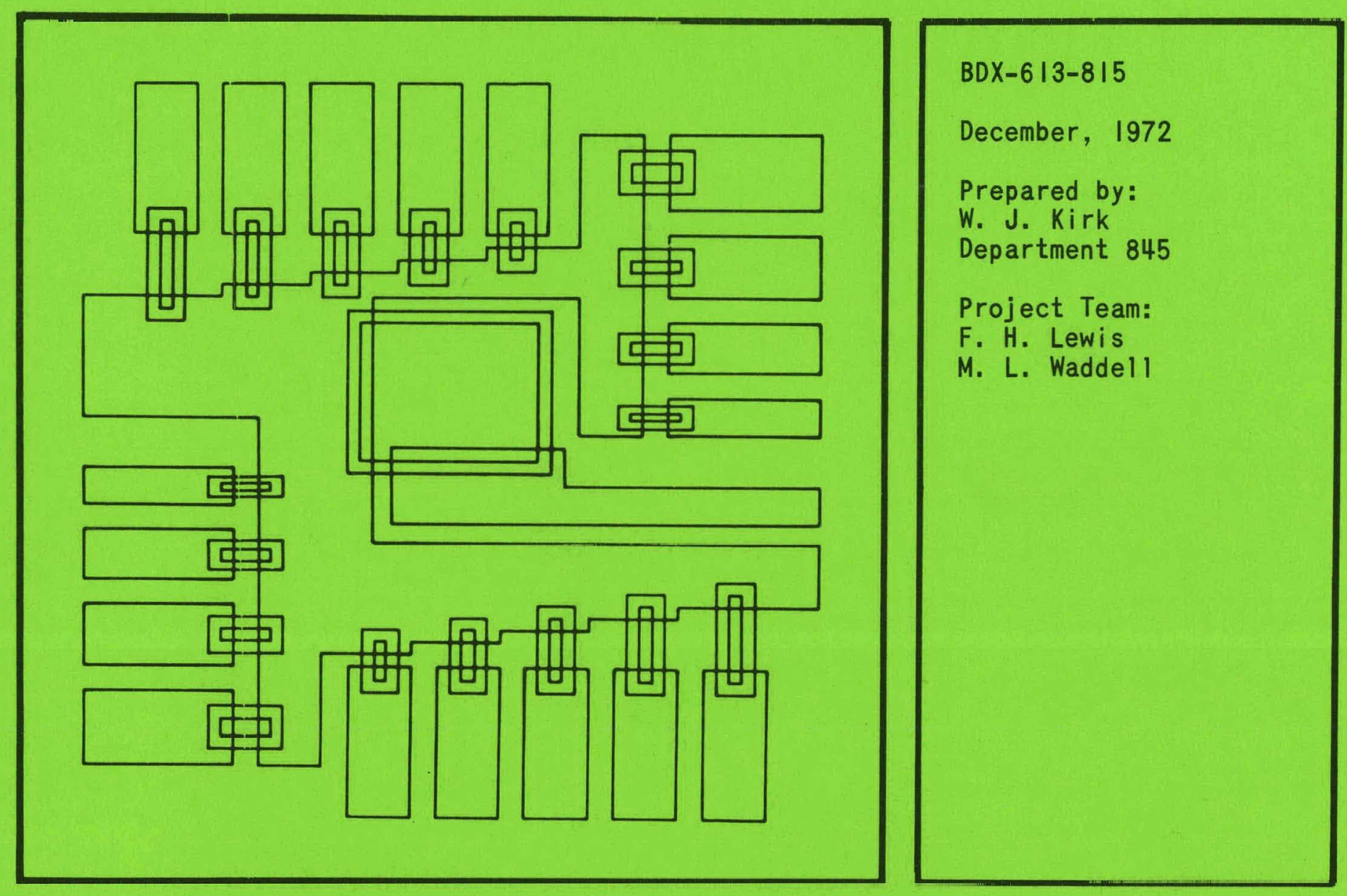

Prepared for the U. S. Atomic Energy Commission Albuquerque Operations Office under Contract Number AT(29-1)-613 USAEC.

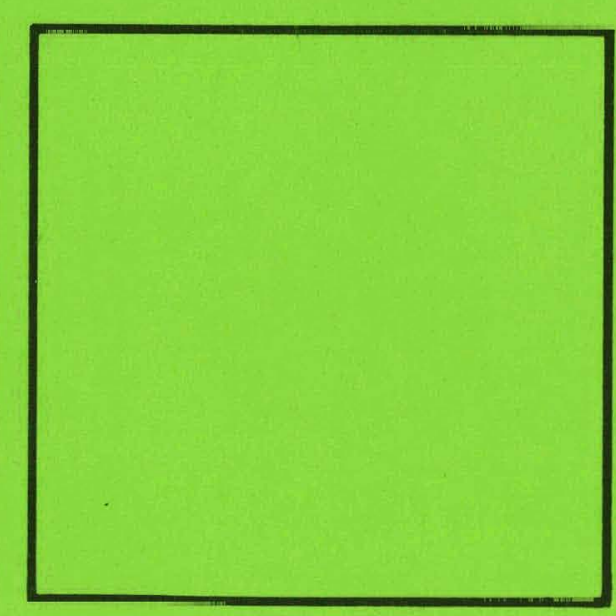




\section{DISCLAIMER}

This report was prepared as an account of work sponsored by an agency of the United States Government. Neither the United States Government nor any agency Thereof, nor any of their employees, makes any warranty, express or implied, or assumes any legal liability or responsibility for the accuracy, completeness, or usefulness of any information, apparatus, product, or process disclosed, or represents that its use would not infringe privately owned rights. Reference herein to any specific commercial product, process, or service by trade name, trademark, manufacturer, or otherwise does not necessarily constitute or imply its endorsement, recommendation, or favoring by the United States Government or any agency thereof. The views and opinions of authors expressed herein do not necessarily state or reflect those of the United States Government or any agency thereof. 


\section{DISCLAIMER}

Portions of this document may be illegible in electronic image products. Images are produced from the best available original document. 


\section{JUNCTION FIELD EFFECT TRANSISTOR DEGRADATION CAUSED BY ELECTROSTATIC DISCHARGE}

$\mathrm{BDX}-613-815$

Distributed December 1972

Project Leader:

W. J. Kirk

Department 845

Project Team:

F. H. Lewis

M. L. Waddell

\section{NOTICE}

This report was prepared as an account of work sponsored by the United States. Government. Neither the United States nor the United States Atomic Energy Commission, not any of their elipluyees, nor any of their contractors, subcontractors, or their employees, makes any warranty, express or implied, or assumes any legal liability or responsibility for the accuracy, completeness or usefulness of any information, apparatus, product or process disclosed, or represents that its use would not infringe privately owned rights. 
THIS PAGE

\section{WAS INTENTIONALLY \\ LEFT BLANK}




\section{JUNCTION FIELD EFFECT TRANSISTOR DEGRADATION CAUSED BY ELECTROSTATIC DISCHARGE}

BDX-613-815, UNCLASSIFIED, Distributed December 1972

Prepared by W. J. Kirk, D/845

Electrostatic buildup of several hundred volts on the body of an operator is common in a low-humidity environment. This charge across measured 100 - to 400-pF distributed capacitances of the human body may be discharged into a low-current FET, thereby degrading or destroying the gate-drain junction. Experiments have shown that static charges as low as 140 volts may damage JFET junctions and that normal body equivalent series resistance (less than 1000 ohms) does not limit the flow of current significantly. Safeguards against the effects of static discharge on JFET junctions during assembly and handling are therefore necessary.

This report was prepared as an account of work sponsored by the United States Government. Neither the United States nor the United States Atomic Energy Commission, nor any of their employees, nor any of their contractors, subcontractors, or their employees, makes any warranty, express or implied, or assumes any legal liability or responsibility for the accuracy, completeness or usefulness of any information, apparatus, product or process disclosed, or represents that its use would not infringe privately owned rights.
THE BENDIX CORPORATION

KANSAS CITY DIVISION

KANSAS CITY, MISSOURI

A prime contractor for the

Atomic Energy Commission

Contract Number AT(29-1)-613 USAEC 
THIS PAGE

\section{WAS INTENTIONALLY LEFT BLANK}


SUMMARY ........................

DISCUSSION ....................... 11

SCOPE AND PURPOSE . . . . . . . . . . . . 11

ACTIVITY. ................... 11

JFET Static Damage . . . . . . . . . . . 11

Energy Storage on the Human Body. . . . . . . . . . 19

ACCOMPLISHMENTS . . . . . . . . . . . . 24

FUTURE WORK .................... 24

REFERENCES ................... 25 


\section{THIS PAGE \\ WAS INTENTIONALLY \\ LEFT BLANK}




\section{ILLUSTRATIONS}

Figure

Page

1 Static Discharge Test Circliit . . . . . . . . . . . 13

2 JFET Test Circuits. . . . . . . . . . . . . . . 14

3 Degraded 2N2608 FET (P77698) . . . . . . . . . . 17

$4 \quad$ Method of Measuring Human Body Equivalent Series

Resistance and Distributed Capacitance . . . . . . . . 22

TABLES

Number

Page

1 Effect of Capacitance and Voltage Polarity on Static

Catastropic Failure of JFE''s . . . . . . . . . . 12

2 Effects of Capacitance and Voltage on JFET Degradation . . .

3 Published Values of Body Capacitance and Resistance . . . .

4 Human Body Capacitance to Earth Ground or to Metal Plate. .

5 Body Distributed Capacitance and Equivalent Series . . . .

Effects of Series Resistance and Inductance on 2N41184 JFET Static Degradation. . . . . . . . . . . . . 
THIS PAGE

WAS INTENTIONALLY

LEFT BLANK 


\section{SUMMARY}

A literature search and physical experiments were conducted tọ determine the effects of electrostatic discharge on four types of junction field effect transistors (JFET's) that are required in a new electronic assembly. These JFET's had not been used previously in a low-humidity manufacturing environment; therefore, preparations for production required that processes and facilities necessary to ensure product performance and reliability be evaluated. Common knowledge that the gate-drain junction of .FET's is susceptible to damage from electrostatic discharge prompted special attention to this phase of the work.

Electrical models of the human body were devised and tests were conducted to determine approximate values of capacitance and equivalent series body resistance that can be expected at typical work stations, the electrostatic potentials that can be expected on the bodies of operators, and the effects of discharging electrostatic energy into the high-impedance low-current JFET's that are to be used in this assembly.

Tests to determinc the effects of electrustatic discharge on the JH'ET'S resulted in several significant findings:

- A $2 \mathrm{~N} 4118 \mathrm{~A}$, the most susceptible of the four types tested, was degraded by a static discharge from the body of an operator charged to only 140 volts: This energy level is about $1 / 100$ of that required to detonate an explosive hydrocarbon gas. 14

Many samples of the four types of JFET's were degraded by static voltage, but remained functional in assemblies. This posed a potential reliability problem which was solved by including an additional test to the in-process inspection procedure.

- Measured operator body capacitances of 90 to $405 \mathrm{pF}$ were much more significant than measüred equivalent body series resistances of 87 to 190 ohms when considering the JFET static damage potential.

Study and evaluation of static prevention methods will be continued to determine the most effective means of preventing JFET junction damage in production assemblies. Humidity control, operator clothing, fixturing, and grounding techniques such as conductive floors and work surfaces are some of the aspects to be considered. 


\section{THIS PAGE \\ WAS INTENTIONALLY \\ LEFT BLANK}




\section{DISCUSSION}

\section{SCOPE AND PURPOSE}

This work was conducted as a part of preparations for manufacturing an electronic assembly that contains four junction field effect transistors (JFET's) which had not been used previously in a low-humidity production environment. Common knowledge that FET's are susceptible to junction damage caused by electrostatic discharge prompted this investigation to determine the problems that might be encountered and the safeguards necessary to ensure product reliability.

The electrostatic-control work includes

- Determining the effects of various static voltages on the JFET's,

- Establishing the maximum allowable value of static voltage for each of the four JFET types, and

- Developing procedures to ensure that allowable static voltage values are not exceeded in environments of 5- to 50-percent rh.

When the necessary static-control techniques have been developed, they will be applied to

- JFET lead forming and pretinning,

- Fixturing and assembly operations,

- JFET and assembly testing, and

- Special JFET packaging, both in and out of assemblies.

\section{ACTIVITY.}

\section{JFET Static Damage}

The four JFET types were tested to determine which is the most susceptible to damage from static electricity. A capacitor was charged to a known voltage, then discharged through the gate-drain junction of the JFET, as shown in Figure 1. The results of those tests ('Table 1) show that the $2 \mathrm{~N} 4118 \mathrm{~A}$ is the most susceptible of the four types to static discharge and that all of the four types are more sensitive to reverse breakdown polarity than to forward conducting polarity. 
Table 1. Effects of Capacitance and Voltage Polarity on Static Catastropic Failure of JFET's

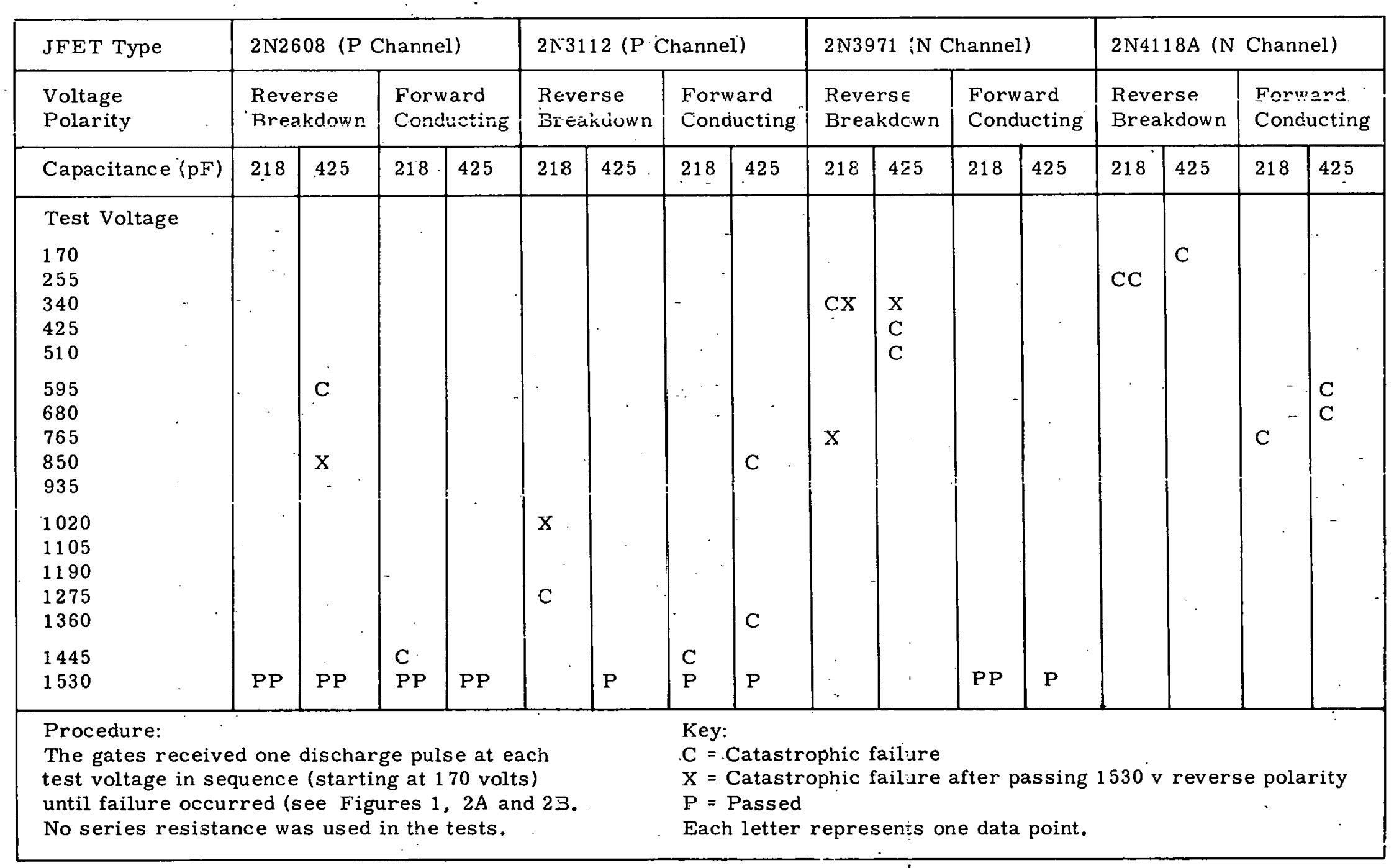




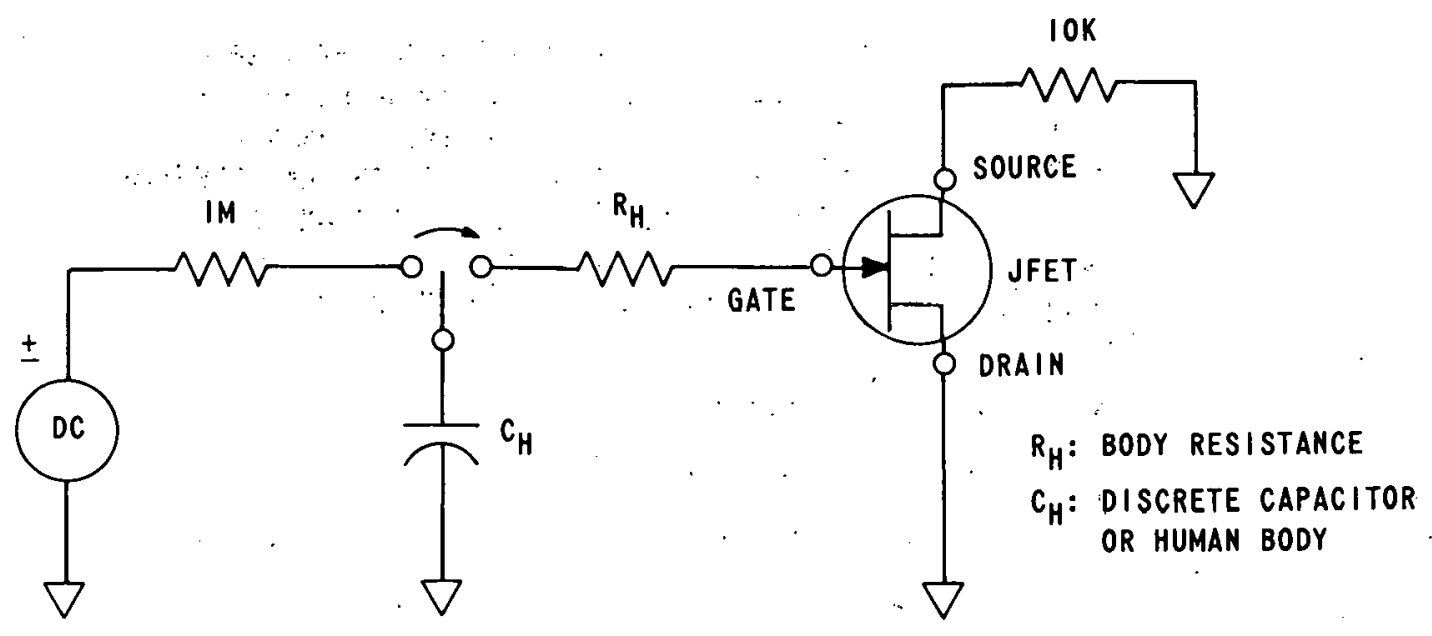

Figure 1. Static Discharge Test Circuit

The failure criterion for these first tests was a change in either turn-on voltage (gate-drain) or saturated source current. The test circuits are shown in Figure 2.

The results of this catastrophic test were so inconsistent and the voltages were so high that the validity of the test method was reviewed. Although the method simulated the product usage, it did not indicate the point of first transistor degradation. Therefore, four 2 N2608 transistors that still passed the catastrophic failure test after stressing to \pm 1500 volts were subjected to complete electrical tests which revealed that the gate reverse breakdown voltage was grossly reduced. Postmortems of these units revealed dark brown burn paths between the gate and the drain elements, as shown in Figure 3.

The test circuit was modified as shown in Figure $2 \mathrm{C}$ to use gate breakdown voltage as the test criterion. This part of the work showed that it is possible that a degraded JFET in an assembly might not be detected by the present product test procedure. Since long-term product reliability is a paramount requirement, these tests emphasized the need for static protection.

Sensitivity to reverse breakdown voltage was used as the criterion to obtain the refined data of the effects of static voltage shown in Table 2. Most of the data points represent less-than= catastrophic degradation. 


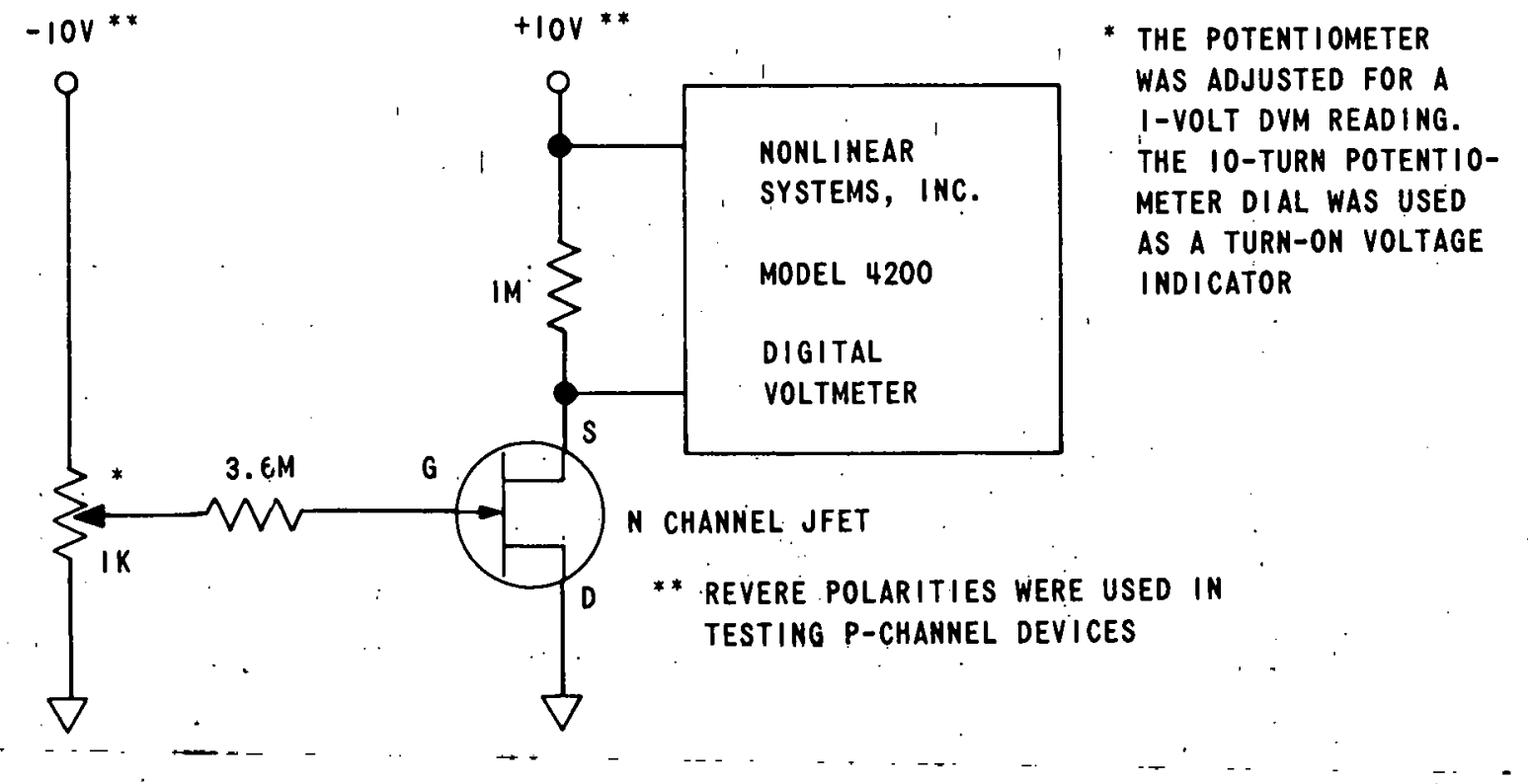

A. TURN-ON VOLTAGE FOR I-MICROAMPERE SOURCE. CURRENT

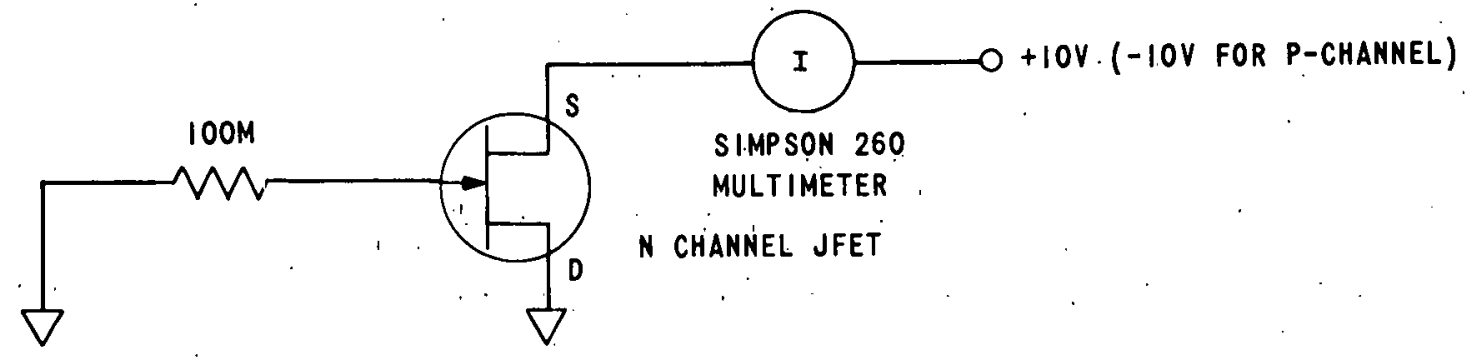

B. SATURATED SOURCE CURRENT

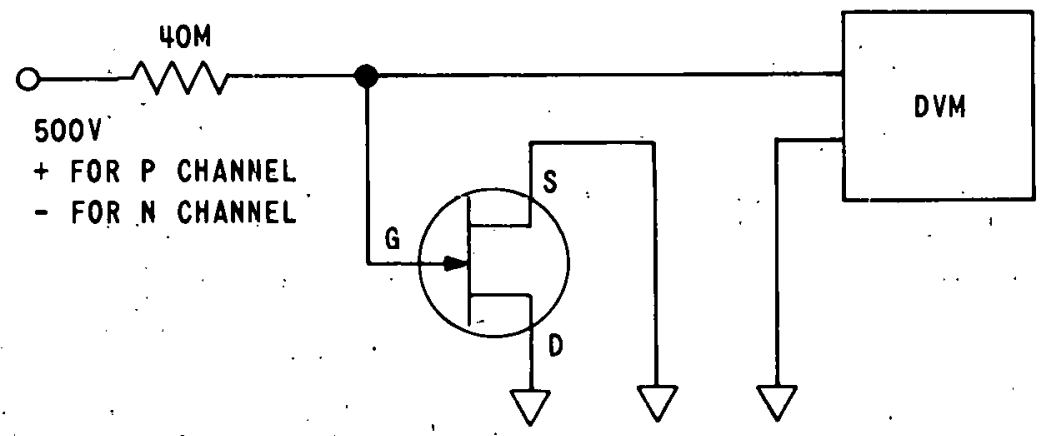

C. REVERSE BREAKDOWN VOLTAGE

Figure 2. JFET Test Circuits 
Table 2. Effects of Capacitance and Voltage on JFET Degradation

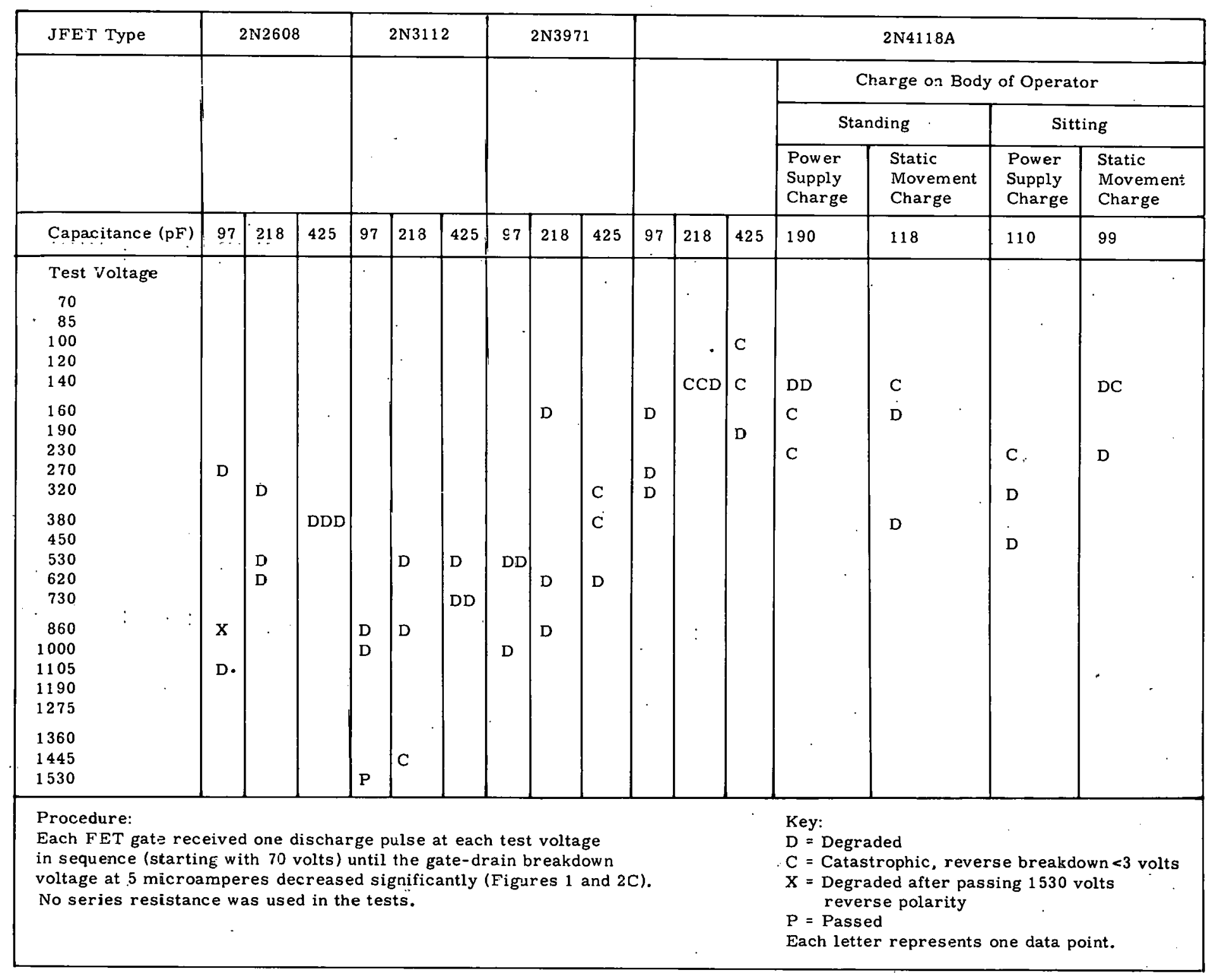




\section{THIS PAGE}

\section{WAS INTENTIONALLY LEFT BLANK}




\section{UNCLASSIFIED \\ P77 6 y JUL 121972}

$d$ 
THIS PAGE

WAS INTENTIONALLY

LEFT BLANK 
In the first Bendix controlled-condition experiments a discharge from a standing operator charged to 140 volts degraded a 2 N41184 JFET. The energy discharge from a $218 \mathrm{pF}$ capacitor charged to 140 volts is 2.1 microjoules, about $1 / 100$ of that required to detonate an explosive hydrocarbon gas. 14

The effect of the static discharge from the measured 190-pF distributed capacitance of a standing person on $2 \mathrm{~N} 4118 \mathrm{~A}$ degradation was essentially the same as that from a 218-pF discrete capacitor. The effect of the measured $110-\mathrm{pF}$ capacitance of an operator in sitting position was comparable to that of a $97-\mathrm{pF}$ discrete capacitor. Since these capacitance values are not identical and body equivalent series resistance was not considered, the comparisons are only approximate. Exact values of body capacitance and voltage charge vary between individuals and depend on such factors as clothing, movement, proximity to surrounding objects, and moisture content in the atmosphere.

\section{Energy Storage on the Human Body}

A reasonably accurate energy-storage model of the human body must be used to obtain conclusive results of the effects of static energy on JFET's. A review of published literature revealed that a rather wide range of body capacitance and resistance values have been used by others. $1-14$ These published values are listed in Table 3. Equivalent body resistance was reported to be a function of voltage, 3,5 but most models ignored that consideration.

Several different test methods were used to measure body capacitance under a variety of conditions. : The results, shown in Tables 4 and 5 , indicate that measured values are dependent on the test location and the test method used; however, the values obtained were in general agreement with the values given in the literature. Capacitances of 97,218 , and $425 \mathrm{pF}$ used to obtain the data in Table 2 appear representative of the values expected at a typical work station.

The RC discharge method used to measure apparent body resistance was prompted by Petrick, 8 although the technique was altered slightly, as shown in Figure 4. The test results shown in Table 5 are somewhat inaccurate because of the methods used, but are considered sufficiently accurate for use in static tests. The apparent body resistance of one person varied from 87 to $190 \mathrm{ohms}$, and did not appear significantly voltage sensitive. The data in Table 6 indicate that body resistances below at least 1000 ohms offer no significant FET protection. For that reason, the effects of body resistance will not be investigated further. A slightly conservative but realistic value of 100 ohms will be assumed for continued work on this project.

Text continues on page 26 . 
Table 3. Published Values of Body Capacitance and Resistance

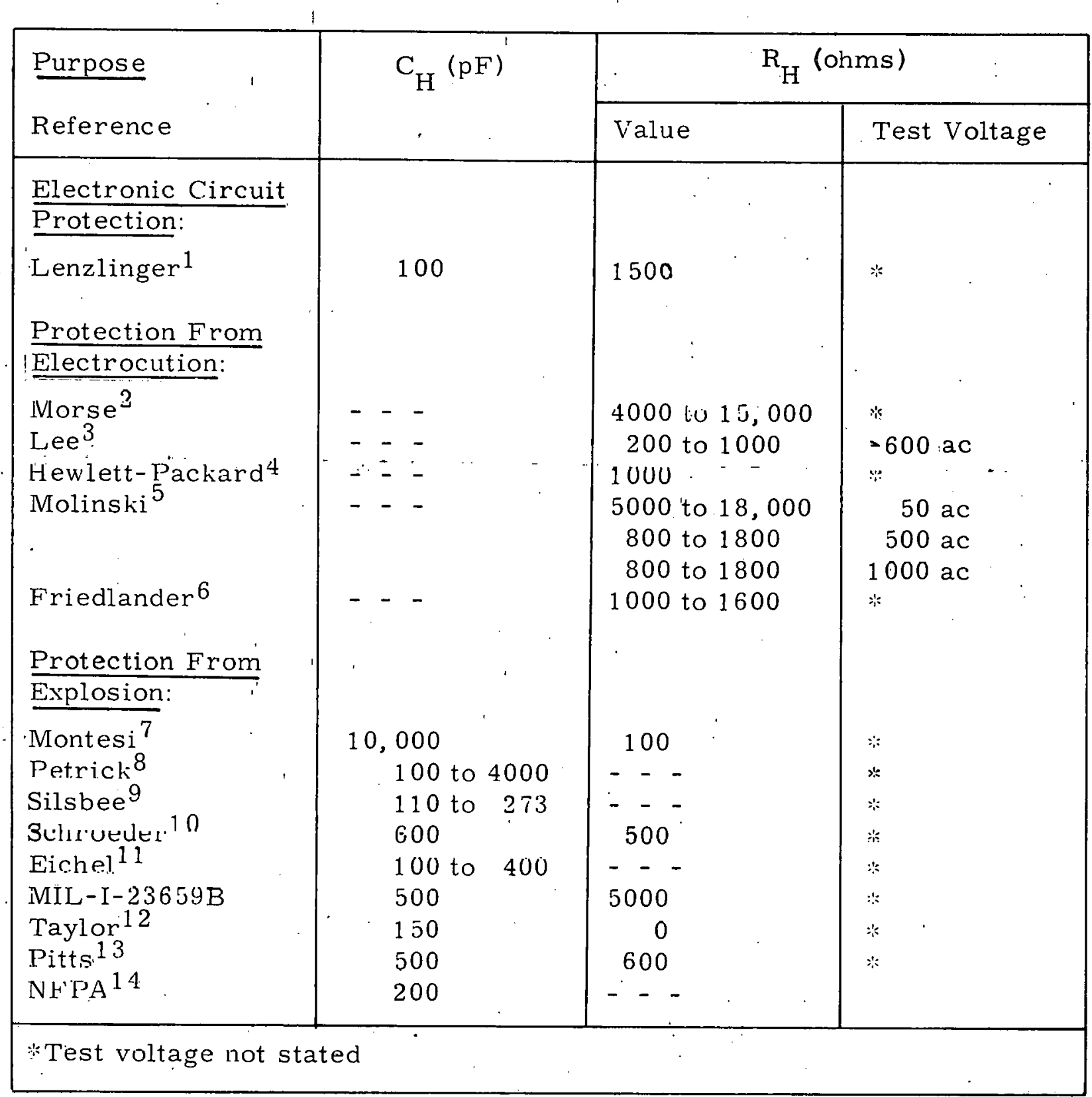


Table 4. Human Body Capacitance to Earth Ground or to Metal Plate

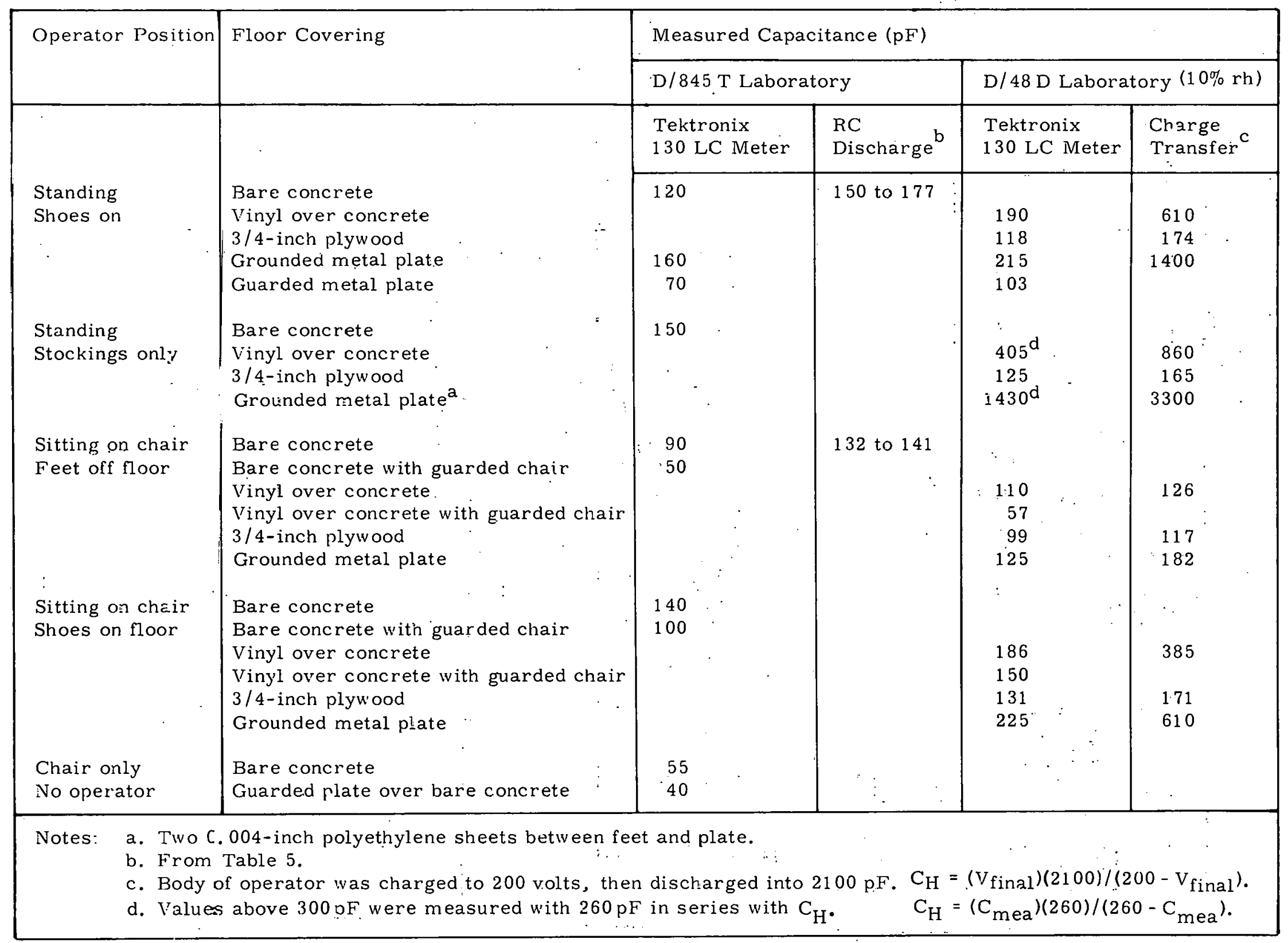



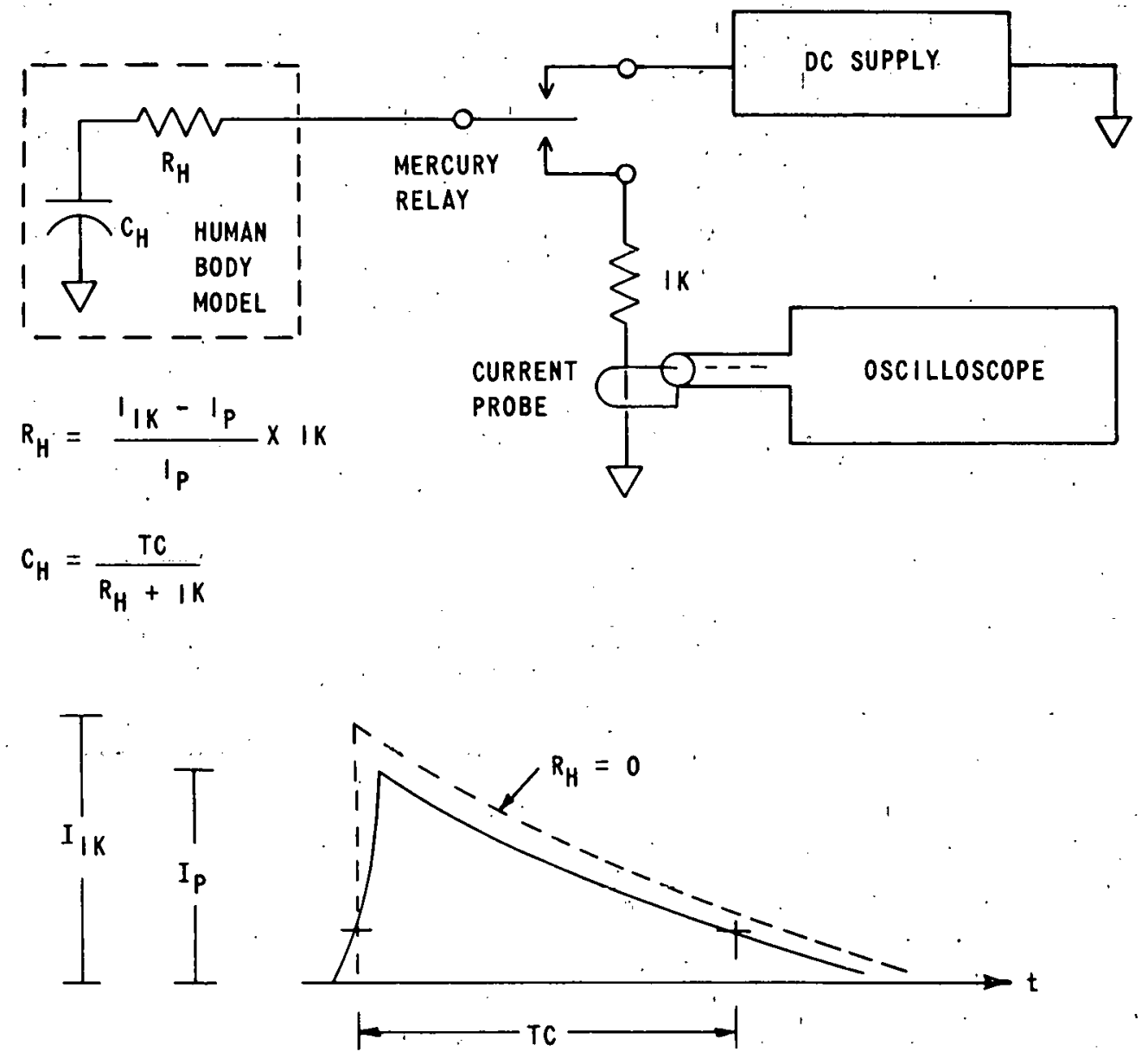

Figure 4. Method of Measuring Human Body Equivalent Series Resistance and Distributed Capacitance 
Table 5. Body Distributed Capacitance and Equivalent Series Resistance

\begin{tabular}{|c|c|c|c|c|c|}
\hline Test Condition & Voltage & $\mathrm{I}_{\mathrm{pk}}(\mathrm{A})$ & $\begin{array}{l}\text { Time Constant } \\
\text { (microsec) }\end{array}$ & $\mathrm{R}_{\mathrm{H}}$ (ohms) & $\mathrm{C}_{\mathrm{H}}(\mathrm{pF})$ \\
\hline \multirow{4}{*}{$\begin{array}{l}\text { Standing on bare } \\
\text { concrete floor }\end{array}$} & 200 & 0.18 & 0.18 & 110 & 162 \\
\hline & 500 & 0.44 & 0.20 & 135 & 177 \\
\hline & 1000 & 0.88 & 0.18 & 135 & 159 \\
\hline & 2000 & 1.68 & 0.418 . & 190 & 150 \\
\hline Sitting on chair & 200 & 0.176 & 0.16 & 135 & 141 \\
\hline on bare concrete & 1000 & 0.88 & 0.15 & 135 & 132 \\
\hline feet off floor & 2000 & 0.92 & 0.15 & 87 & 138 \\
\hline \multicolumn{6}{|l|}{ Calibration: } \\
\hline $135 \mathrm{pF}$ & 500 & 0.48 & 0.16 & 40 & 135 \\
\hline $270 \mathrm{pF}$ & 500 & 0.50 & 0.31 & 0 & 270 \\
\hline
\end{tabular}

Table 6. Effects of Series Resistance and Inductance on 2N4118A JFET Static Degradation

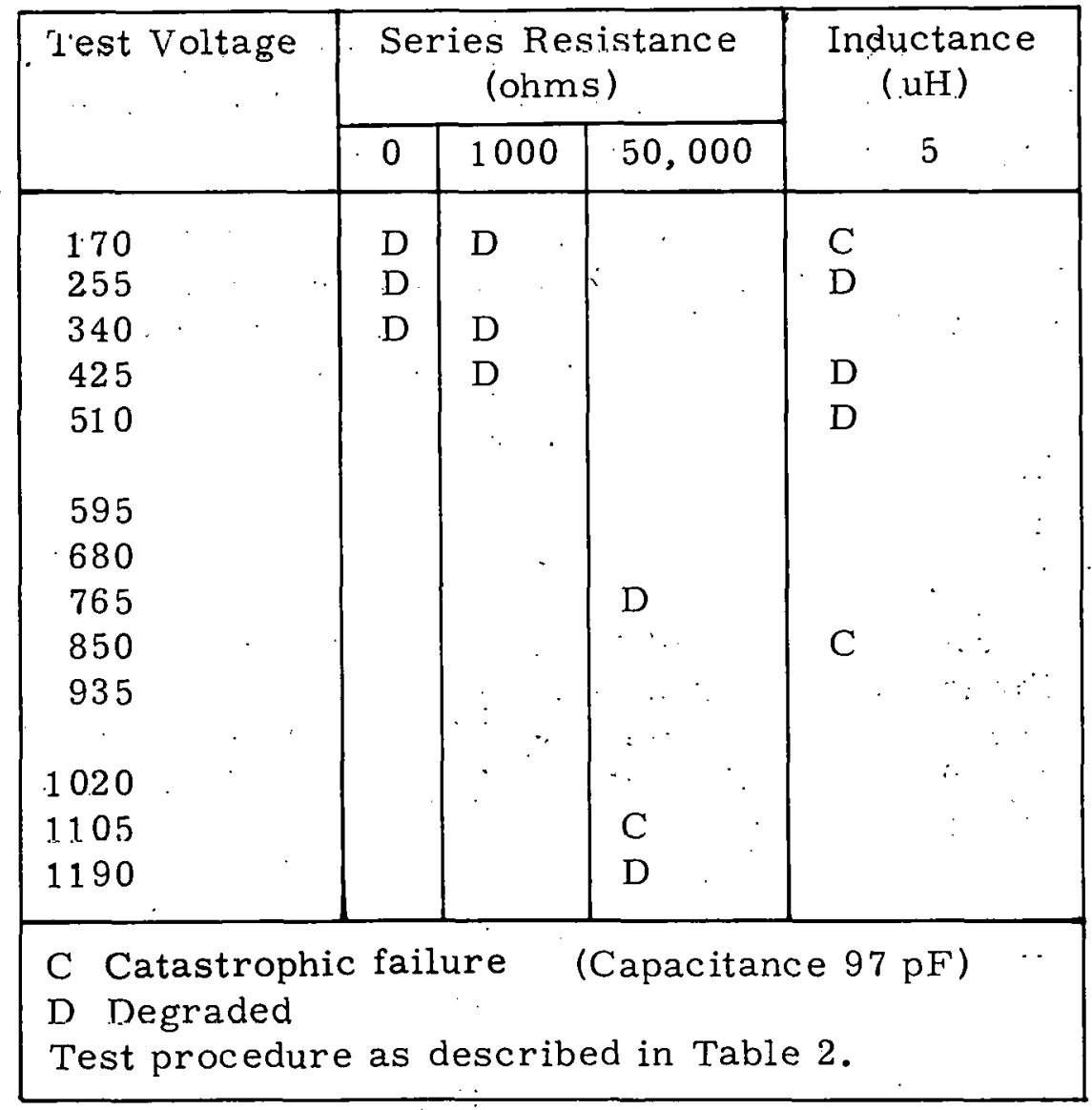




\section{ACCOMPI,ISHMENTS}

Evaluation of static damage in junction field effect transistors has yielded the following conclusions.

- The 2N4118A JFET's can be degraded by contact with the body of an operator charged to 140 volts.

- All of the four types of JFET's could have been significantly degraded before passing the catastropic failure tests or during the tests.

Becaise this is a potential reliability problem, an additional test will be included in the product test procedure to detect a decrease in gatedrain reverse breakdown voltage.

- The 2N4118A is significantly more susceptible than the 2N2608, the 2N3112, or the 2N3971 to static damage from extraneous sources.

- The static energy required to degrade a 2N4118A JFET is approximately $1 / 100$ of that required to detonate a sensitive explosive gas.

- The polarity of the static voltage applied to the gate-drain junction of the JF'ET is significant. The reverse (breakdown) polarity produces greate $r$ damage than the forward (conducting) polarity.

- Series resistances up to at least 1000 ohms, which encompass the range of apparent body resistance, have no appreciable effect on the value of static voltage required to degrade a.JFET.

A series RC circuit was devised to approximate the discharge mechanism of the human body. Equivalent body resistance values of 87 to $190 \mathrm{ohms}$ and body distributed capacitances of 90 to $405 \mathrm{pF}$ were measured. These values are believed representative of those that can be expected at typical work stations.

\section{FUTURE WORK}

Additional 2N4118A JFET static degradation tests will be conducted to accumulate sufficient data to increase statistical confidence in the data listed in Tables 2 and 5, and the findings of this investigation will be applied to static control measures. required to protect the JFET's from static damage during manufacturing operations. 


\section{REFERENCES}

1 Martin Lenzlinger, "Gate Protection of MIS Devicés," IEEE.Transactions.: on Electron Devices, Vol. ED-18, No. 4, April 1971, pp 249-257. .

A. R. Morse, comment on "Field Treatment of Electric Shock Cases-1," by W. B. Kouwenhoven, and W. R. Milnor, AIEE Transactions Power Apparatus and Systems, Vol. 76, April 1957, pp 82-87.

${ }^{3}$ Ralph H. Lee, "Electrical Safety in Industrial Plants," IEEE Spectrum, June 1971, pp 51-55. $\therefore$

${ }^{4}$ "Using Electrically-Operated Equipment Safely with the Monitored Cardiac Patient," Hawlett-Packard Company, Waltham, Mass., March 1970, p 22.

${ }^{5}$ A. E. Molinski, "Effects of Electricity on the Human Body, "Mining Congress Journal, Vol. 56, No. 7, July 1970, pp.64-68.

${ }^{6}$ Gordon D. Friedlander, "Electricity in Hospitals: Elimination of Lethal Hazards, "IEEE Spectrum, September 1971, pp 40-51.

${ }^{7}$ Louis J. Montesi, "The Development of a Fixed Gap Electrostatic Spark Discharge Apparatus fór Characterizing Explosives," Proc. Sixth Symposium on Electroexplosive Devices, San Francisco, Calif. , July 8-10, 1969, pp 2-8.1.

${ }^{8}$ John T. Petrick, "Discharge of an Electrostatically Charged Human, "Proc. Sixth Symposium on Electroexplosive Devices, San Francisco, Calif, July 8-10, 1969, pp 3-5.1.

9 Francis B. Silsbee, "Static Electricity, "National Bureau of Standards Circular C438, June 10, 1942, p 23.

${ }^{10}$ C. F. Schroeder, Jr., "Energy Transfer in Electrostatic Arcs, "Proc. Fifth Symposium on Electroexplosive Devices, June 13-14, 1967, p $\overline{2-5.1}$. 
${ }^{11}$ F. G. Eichel, "Electrostatics, " Chemical Engineering, March 13, 1967, , pp 153-167.

12 Boyd C. Taylor, "Electrostatic-Insensitive Detonator for Precise Syncronization, " Proc. Sixth Symposium on Electroexplosive Devices, San Francisco, Calif., July 8-10, 1969, pp 1-10.1.

${ }^{13}$ L. D. Pitts, "Demythologizing Electrostatics," Proc. Sixth Symposium on Electroexplosive Devices, San Francisco, Calif., July 8-10, 1969, pp 3-7,1.

14 "Static Electricity, "National. Fire Codes, Vol. 9, No. 77, 1966, National Fire Protection Association, Boston, 1970-71, pp 77-44.

${ }^{15}$ Ibid, pp $77-10$. 